\title{
Strength Prediction of Lamellar Graphite Iron: From Griffith's to Hall-Petch Modified Equation
}

\author{
Vasilios Fourlakidis ${ }^{1, a^{*}}$, Lucian V. Diaconu ${ }^{2, b}$ and Attila Diószegi ${ }^{2, c}$ \\ ${ }^{1}$ Swerea SWECAST AB, P.O. Box 2033, SE-550 02 Jönköping, Sweden \\ ${ }^{2}$ Jönköping University, Dept. of Mechanical Engineering/Material and Manufacturing Casting, Box \\ 1026, SE-551 11 Jönköping, Sweden \\ avasilios.fourlakidis@swerea.se, blucian-vasile.diaconu@ju.se, cattila.dioszegi@ju.se
}

Keywords: Tensile strength, lamellar graphite iron, primary austenite, pearlite spacing.

\begin{abstract}
Traditionally, ultimate tensile strength (UTS) is used as the main property for the characterization of lamellar graphite iron (LGI) alloys under static loads. The main models found in the literature for predicting UTS of pearlitic lamellar graphite iron are based on either regression analysis on experimental data or on modified Griffith or Hall-Petch equation.

In pearlitic lamellar graphite iron the primary austenite dendritic network, transformed to pearlite, reinforces the bulk material while the distance between those pearlite grains, defines the maximum continuous defect size in the bulk material. Recently the novel parameter of the Diameter of Interdendritic Space has been used to express the flow length in a modified Griffith equation for the prediction of the UTS in LGI. Nevertheless this model neglects the strengthening effect of the pearlite lamellar spacing within the perlite grains. A model based on modified Hall-Petch equation was developed in this work. The model considers the effect of both microstructure parameters and covers a broad spectrum of microstructure sizes typical for complex shape castings with various wall thicknesses.
\end{abstract}

\section{Background}

Environmental regulations, economy, high performance and fuel consumption are the main parameters that drive the development of heavy truck engines. Cylinder blocks and cylinder heads are the primary components of these engines and the majority of them are made of lamellar graphite iron (LGI) alloy. The maximum strength of LGI is an essential factor that determines the performance and the fuel consumption of those engines. The dependence between different microstructural parameters and the ultimate tensile strength (UTS) of LGI has been thoughtfully investigated in the past [1-7 and 9] and shows that the UTS can be predicted either by using the Griffith relation [1, 3, 6 and 7] or a modified Hall-Petch equation [9]. The modified Griffith fracture relation is given in Eq. 1 and the Hall-Petch strengthening model is presented in Eq. 2:

$$
\sigma_{\mathrm{UTS}}=\frac{k_{t}}{\sqrt{c}}
$$

Where $\mathrm{c}$ is the flaw length and $\mathrm{k}_{\mathrm{t}}$ is the stress intensity factor of the metallic matrix.

$$
\sigma=\mathrm{k}_{1}+\frac{k_{2}}{\sqrt{d}}
$$

Where $\sigma$ is the yield stress, $\mathrm{k}_{1}$ and $\mathrm{k}_{2}$ are the contributions from other strengthening mechanisms and $d$ is the grain size.

Previous research works $[1,3,6]$ considered that the graphite flakes, dispersed in the metal matrix, behave as Griffith cracks in a brittle type solid and they used the maximum graphite length as the flaw parameter (c) in the Eq. 1. However in a recent work [7] it has been found that the coarseness and the amount of the eutectic phase, as it is expressed by the novel develop parameter of the Hydraulic Diameter of the Inter-dendritic Phase $\left(\mathrm{D}_{\mathrm{IP}}{ }^{\mathrm{Hyd}}\right)$, can be used in the Griffith equation, instead of the graphite length, for the more accurate prediction of the UTS in LGI alloys, see Eq. 3. 
The conclusion was that in LGI the primary dendritic network is the materials main strengthening factor and the entire eutectic phase can be considered as the flaw length. The model obtained covers the whole spectrum of carbon content from eutectic to hypoeutectic composition, solidified at a wide range of different cooling rates.

$$
\sigma_{\mathrm{UTS}}=\frac{1212}{\sqrt{\mathrm{D}_{\mathrm{IP}}^{\mathrm{Hyd}}}}
$$

Nevertheless it is known [8] that the strength of the primary dendritic network can be increased by increasing the pearlite inter-lamellar spacing. Catalina et al [9] considered a tensile strength model for pearlitic LGI, where certain levels of stresses are imposed on the material before a crack is initiated. The proposed equation is based on modified Hall-Petch equation and the UTS is predicted as a function of the maximum graphite length $\left(\mathrm{L}_{\max }\right)$ and the pearlite inter-lamellar spacing $\left(\lambda_{\mathrm{p}}\right)$. The proposed model considered that the constant coefficient $\mathrm{k}_{2}$ in Eq. 2 was influenced mainly by the pearlite inter-lamellar spacing, see Eq. 4. Finally, multiple regression analysis was used to derive the coefficients in Eq. 5.

$$
\begin{aligned}
& \sigma_{\mathrm{UTS}}=\kappa_{1}+\frac{\kappa_{3}+\frac{\kappa_{4}}{\sqrt{\lambda_{\mathrm{p}}}}}{\sqrt{\mathrm{L}_{\max }}} \quad=>\quad \sigma_{\mathrm{UTS}}=\kappa_{1}+\frac{\kappa_{3}}{\sqrt{\mathrm{L}_{\max }}}+\frac{\kappa_{4}}{\sqrt{\mathrm{L}_{\max } \cdot \lambda_{\mathrm{p}}}} \\
& \sigma_{\mathrm{UTS}}=80+\frac{2.25 \times 10^{-3}}{\sqrt{\mathrm{L}_{\max }}}+\frac{1.98 \times 10^{-3}}{\sqrt{\mathrm{L}_{\max } \cdot \lambda_{\mathrm{p}}}}
\end{aligned}
$$

Where $\mathrm{L}_{\max }$ and $\lambda_{\mathrm{p}}$ are in $\mu \mathrm{m}$.

The present work demonstrates the dependence of UTS on the microstructural constituents of: pearlite inter-lamellar spacing and Hydraulic Diameter of the Inter-dendritic Phase. Specifically both microstructural features will be incorporated in a modified Hall-Petch equation for the modeling of UTS.

\section{Experimental Methods}

Detailed description of the experimental methods is presented elsewhere $[10,11]$. Briefly, the experimental layout contained three cylindrical castings each one surrounded by a different material (chill, sand and insulation) intended to provide three different cooling rates, see Fig. 1. The chemical composition and the cooling rates are presented in Table 1 and 2. Two-dimensional heat flow condition was induced by placing an insulation plate at the top and the bottom of the cylindrical castings.

Uniaxial tensile testing was performed on one sample machined from each cylindrical casting. Tensile strength measurements were obtained using dog-bone shaped test bars according to VOLVO standard $5 \mathrm{C} 25$. The tests were conducted at a strain rate of $0.035 \mathrm{~mm} / \mathrm{s}$ and at room temperature. The positions of the tensile bars and the section surface for microstructure investigation were within the equiaxed zone and hence the results obtained are not systematically influenced by the primary austenite orientation.

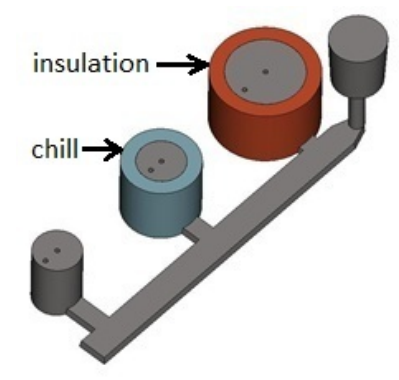

Figure 1: Schematic representation of the experimental casting. 
Table 1: Chemical composition (wt $\%)$ and carbon equivalent $(\mathrm{CE}=\% \mathrm{C}+\% \mathrm{Si} / 3+\% \mathrm{P} / 3)$.

\begin{tabular}{ccccccccc}
\hline Heat & C & Si & Mn & P & S & Cr & Cu & CE \\
\hline 13A & 3.62 & 1.88 & 0.57 & 0.04 & 0.08 & 0.14 & 0.38 & 4.26 \\
13B & 3.34 & 1.83 & 0.56 & 0.04 & 0.08 & 0.15 & 0.37 & 3.96 \\
13C & 3.05 & 1.77 & 0.54 & 0.04 & 0.08 & 0.14 & 0.36 & 3.65 \\
13D & 2.80 & 1.75 & 0.54 & 0.04 & 0.08 & 0.15 & 0.35 & 3.40 \\
\hline
\end{tabular}

Table 2: The experimental solidification rate and time for the different cooling conditions.

\begin{tabular}{cccc}
\hline & High (Chill) & Medium (Sand) & Low (Insulation) \\
\hline Cooling rate $\left[{ }^{\circ} \mathbf{C} / \mathbf{s}\right]$ & 3.5 & 0.8 & 0.2 \\
Solidification time $[\mathbf{s}]$ & 90 & 400 & 1550 \\
\hline
\end{tabular}

The microstructure was examined using an optical microscope. For a quantitative determination of the morphological parameter $\mathrm{D}^{\mathrm{Hyd}}{ }_{\mathrm{IP}}$, the eutectic phase area $\left(\mathrm{A}_{\mathrm{IP}}\right)$ and the periphery of the primary phase (P $\gamma)$, were measured by using image manipulation open source software (GIMP-2) and a commercial image analysis software (Leica Qwin V3 Runner). The parameter $\mathrm{D}_{\text {IP }}^{\mathrm{Hyd}}$ is given as follow [10]:

$$
D_{I P}^{H y d}=\frac{A_{I P}}{P_{\gamma}}
$$

Fig. 2 shows typical images of the investigated microstructure. Fig. 2(a) present the primary phase delimited by the red line. The average diameter of the five larger eutectic cells were measured in each sample, see Fig. 2(b). The pearlite inter-lamellar spacing was measured in a SEM by a linear intercept method. The minimum value was considered to be the correct spacing (perpendicular to the lamellea). As can be seen in Fig. 2(c) the distance between 11 adjacent ferrite lamellas was measured and divided by 10 for the calculation of a single inter-lamellar spacing.

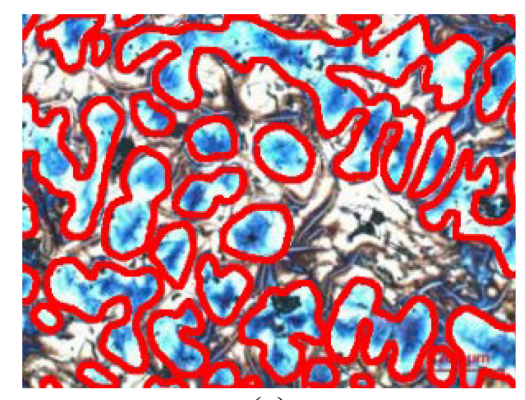

(a)

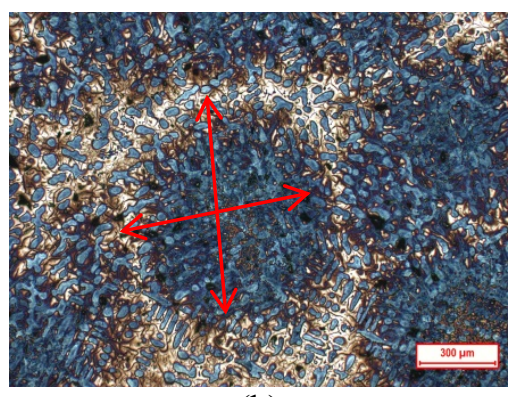

(b)

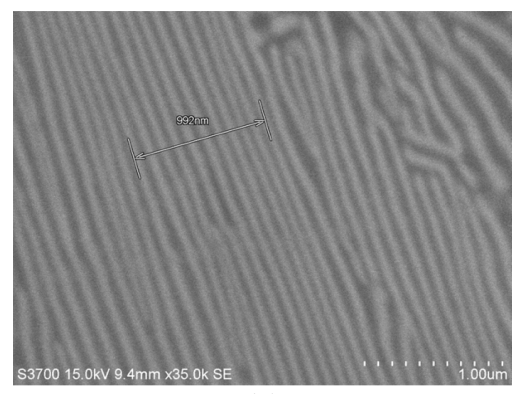

(c)

Figure 2: Typical images of the investigated microstructure. (a) primary austenite dendritic network, (b) eutectic cell and (c) pearlite inter-lamellar spacing.

\section{Results and Discussion}

The microstructure analysis results show that the carbon contents and the cooling rates have a sizeable impact on the scale of the as-cast microstructure. For a given cooling rate, the fraction and the coarseness of the dendritic phase is found to increases with decreasing carbon content. On the other hand the increasing cooling rate causes a decrease in microstructure coarseness while the fraction of primary austenite remains constant.

Microstructure investigation at the cross section of the fracture area shows that the crack path followed the graphite-matrix interfaces and it was passed through the eutectic cells, see Fig. 3. The red arrow in Fig. 3 indicates the direction of the tensile stress. Graphite de-cohesion from the matrix can be also observed. As seen in Fig. 4 the crack advanced at the periphery of some intact dendrite arms meaning that the dendrites poses much higher resistance to the crack growth in comparison with the eutectic phase [10]. 


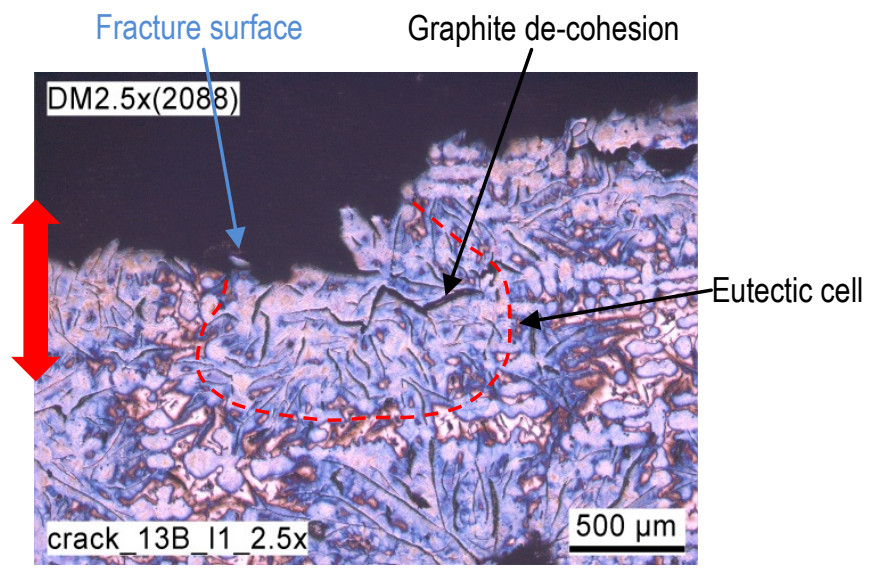

Figure 3: Crack propagation at the inner area of an eutectic cell.

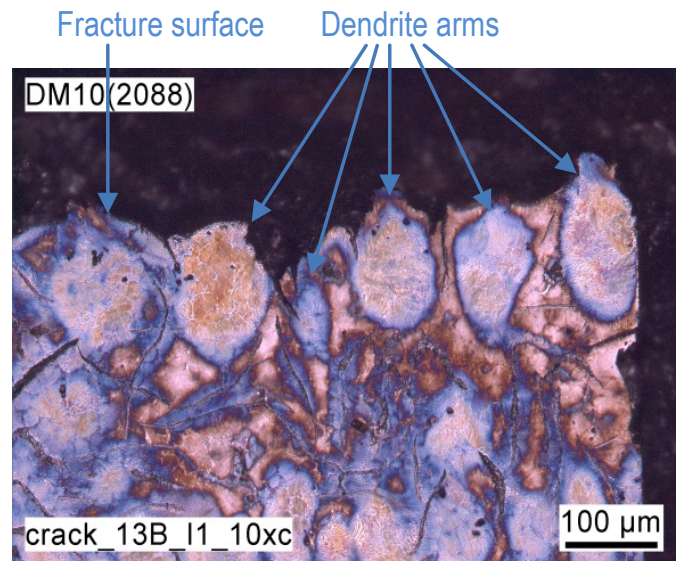

Figure 4: The crack path bypasses the dendrite arms.

The eutectic cells size is influenced by factors such as cooling rate and carbon content or by process related parameters. The diameter of the eutectic cells is believed to be directly proportional to the maximum size of the graphite flakes. The present work data correlation between eutectic cell size and UTS presented in Fig. 5 shows that different cooling rates provide different linear dependencies between the eutectic cell size and UTS. Similar observations were made in a previous work [9] where two different cooling rates resulted to two different relationships between UTS and maximum graphite length. As seen in Fig. 3 the experimental data covers a broad range of eutectic cell sizes. Although the influence of eutectic cell size on UTS is the most discussed relationship in the literature the results of this work indicates that neither the eutectic cell size nor the maximum graphite length can be used as generic parameters for the prediction of the UTS.

A likewise series of linear dependencies between pearlite inter-lamellar spacing and UTS was observed, see Fig. 6. The pearlite inter-lamellar spacing increases with increasing carbon content and the decrease of cooling rate while the UTS shows an inverse linear relationship with the pearlite lamellar spacing for a given cooling rate.

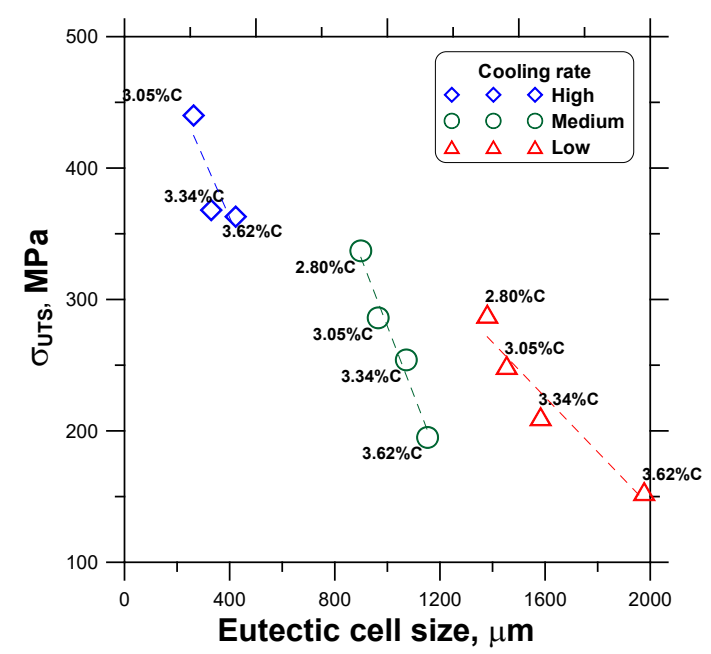

Figure 5: Effect of eutectic cell size on UTS.

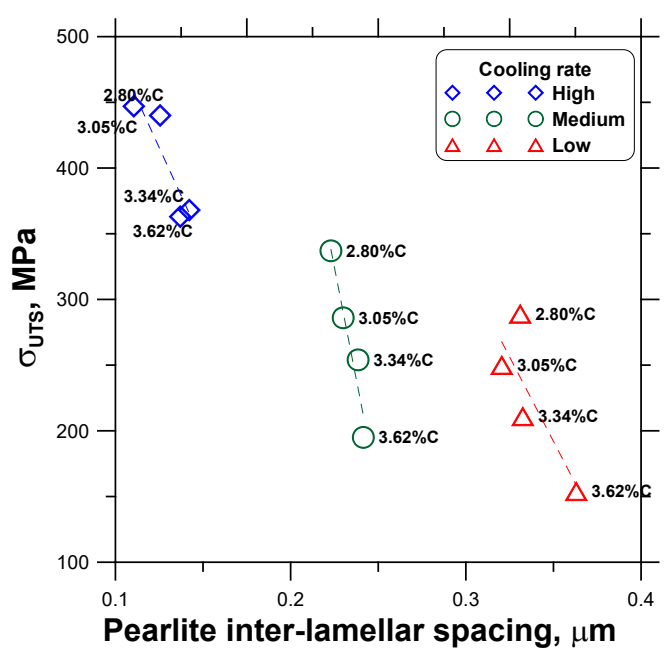

Figure 6: Effect of pearlite spacing on UTS.

Fig. 7 shows that there is an inverse relationship between $\mathrm{D}^{\mathrm{Hyd}}{ }_{\mathrm{IP}}$ and UTS regardless of the cooling rate. Regression analysis provides the following dependency between the tensile strength and the $\mathrm{D}_{\mathrm{IP}}^{\mathrm{Hyd}}$ :

$$
\sigma_{\mathrm{UTS}}=1616 \cdot\left(D_{I P}^{\text {Hyd }}\right)^{-0.586}
$$

where $\mathrm{D}_{\text {IP }}^{\mathrm{Hyd}}$ is in $\mu \mathrm{m}$. 
The relationship obtained indicates that $\mathrm{D}_{\text {IP }}^{\mathrm{Hyd}}$ can be considered as the most influential factor causing the reduction in UTS. It appears that it is not the length of the graphite flakes but rather the fraction and the coarseness of the eutectic area, as expressed by $\mathrm{D}^{\mathrm{Hyd}}{ }_{\mathrm{IP}}$, which is the dominant factor that reduces the UTS in lamellar cast iron alloys.

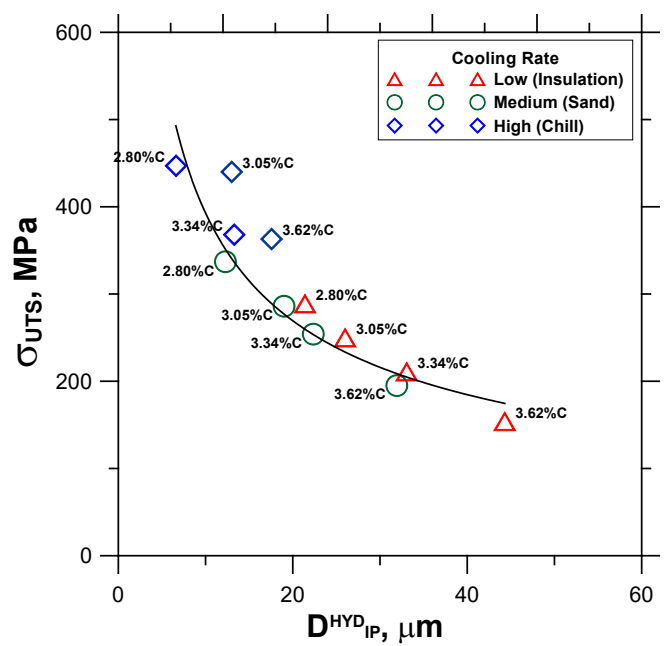

Figure 7: Effect of Hydraulic Diameter of the Inter-dendritic Phase on UTS.

In lamellar graphite iron the eutectic cells can encapsulates a number of individual primary dendrites. This number varies according to the fraction of primary austenite as can be seen in Fig. 8 where it is presented the microstructures of two LGI alloys with 3.6\% (Fig. 8a) and 3.15\% (Fig. 8b) carbon contents that result to $\sim 20 \%$ and $\sim 50 \%$ fraction of primary austenite, respectively. Although both samples have similar eutectic cell size, considerably larger number of primary dendrites traverses across the eutectic cell of the low carbon content sample as can be seen in Fig. 8(b). The depicted observations at Fig.s 3, 4 and 8 were used in Fig. 9 for illustrating schematically a proposed crack mechanism that clarify, in some extent, the found influence of $\mathrm{D}_{\text {IP }}^{\mathrm{Hyd}}$ on UTS.
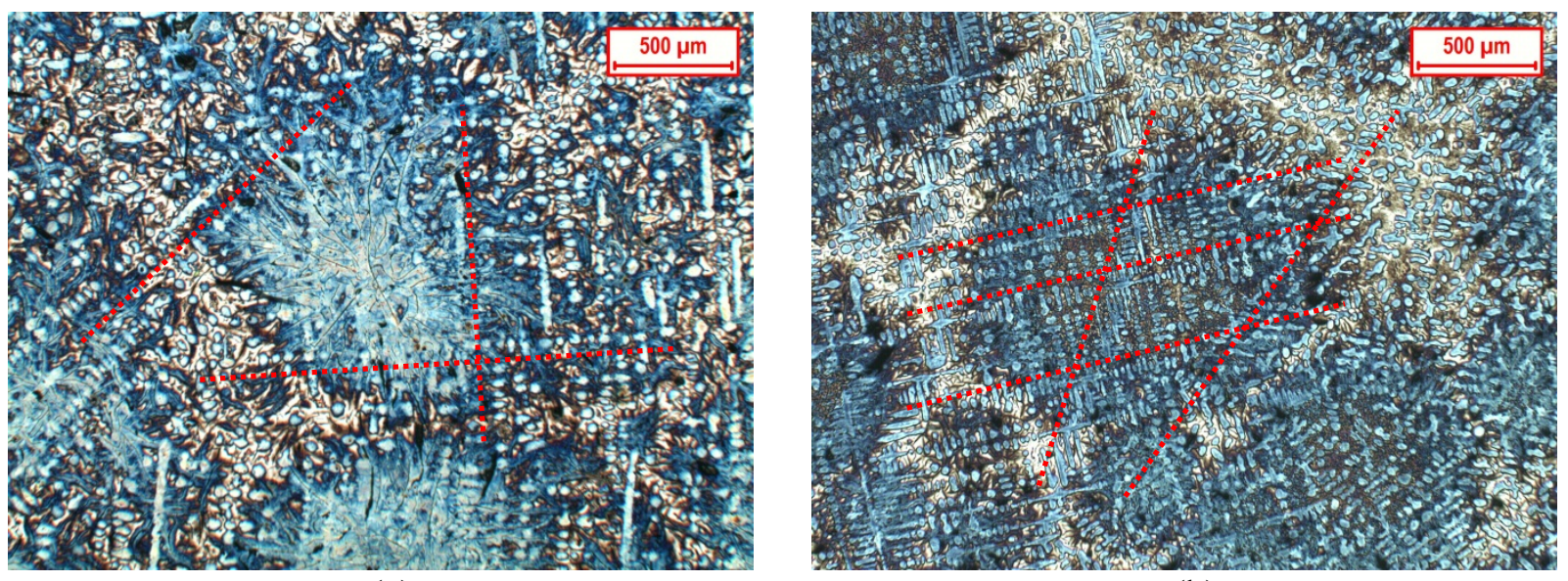

Figure 8: Microstructure of LGI with (a) $3.6 \% \mathrm{C}$ and (b) $3.15 \% \mathrm{C}$. The dashed red lines indicate some of the primary dendrites that crossing the eutectic cells.

Fig. 9 shows a simplistic representation of the microstructure of two LGI alloys produced with different carbon contents and under identical cooling conditions and inoculation treatments. Under those conditions both microstructures will have the same eutectic cells size and pearlite interlamellar spacing but different $\mathrm{D}_{\text {Hyd }}^{\mathrm{Hyd}}$. If a tensile force is applied on the microstructure a crack will start to form at a certain stress level. This crack will propagate relatively easy through the numerous interconnected graphite particles that are embedded in the metallic matrix of the eutectic cell, see Region 1 in Fig. 9. Contrary when the crack reaches a primary dendrite (see Region 2 in Fig. 9) the relatively rapid crack extension will be halted due to the fact that much larger stresses are required for the fracture of this phase. The magnitude of the additional stress is proportional to the pearlite 
inter-lamellar spacing. Thus it can be assumed that for different carbon contents the UTS is related to fraction eutectic and it can oscillate independently of the eutectic cell size. For example the LGI 2 microstructure in Fig. 9 can be considered stronger than the LGI 1 due to the larger number of primary dendrites that exist within the eutectic cell. The $\mathrm{D}^{\mathrm{Hyd}}{ }_{\text {IP }}$ parameter expresses the length scale of eutectic phase and it is more suitable to be related with the UTS. Obviously, not only the size of the eutectic phase but also the coarseness of the microstructure has a crucial effect on the UTS. This complex microstructure interrelation it is expressed by the $\mathrm{D}^{\mathrm{Hyd}}{ }_{\text {IP }}$ parameter. For example Fig. 10 shows the microstructure of the 13D-insulation and 13C-Sand sample. As seen in Table 3 both samples have approximately the same UTS although there is a significant difference in their

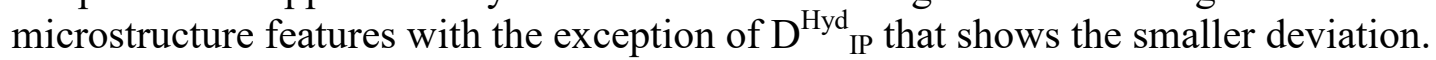

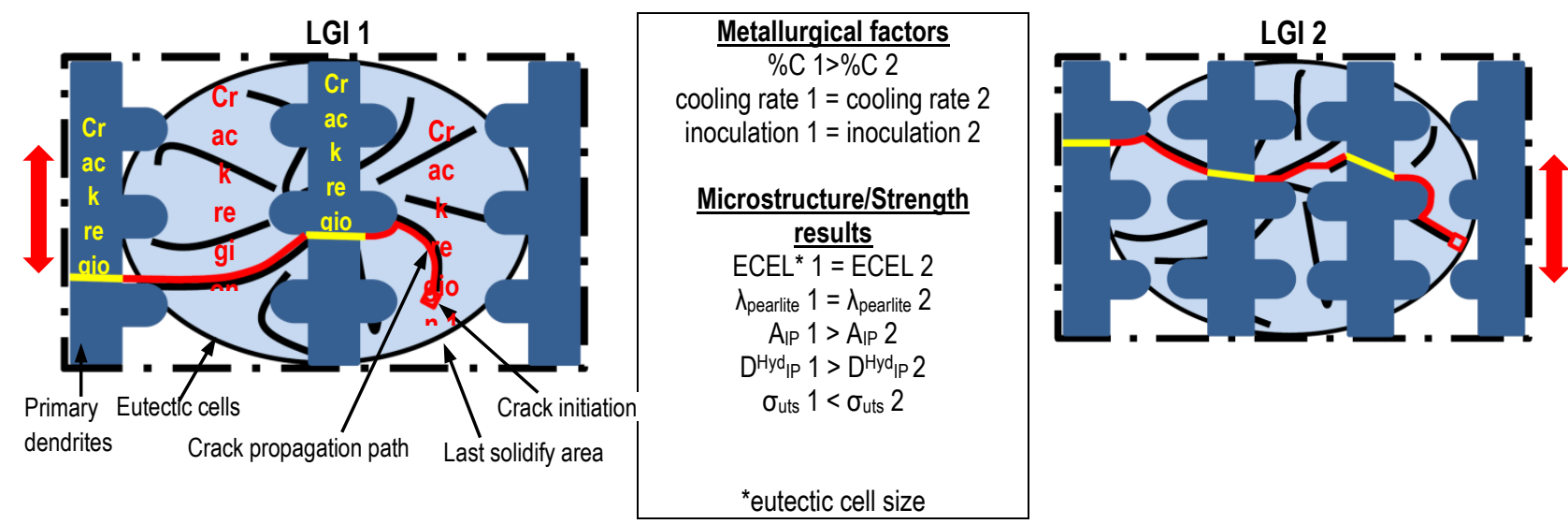

Figure 9: Schematically representation of the crack mechanism in LGI. The red arrows indicate the direction of the tensile stress.

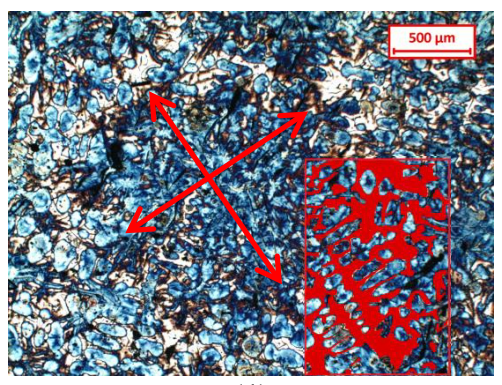

(1)

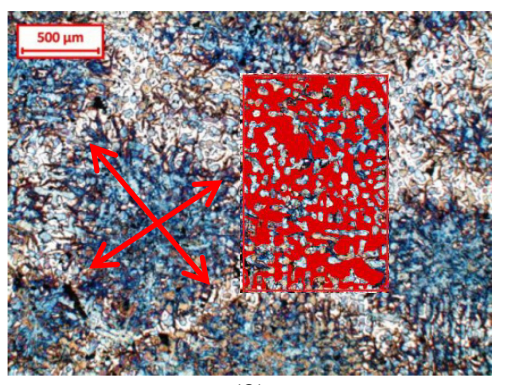

(2)

Table 3: Microstructure data and UTS.

\begin{tabular}{|c|c|c|c|}
\hline & C13D & $\mathrm{C} 13 \mathrm{C}$ & Difference [\%] \\
\hline$f \gamma[\%]$ & 50 & 60 & 25 \\
\hline $\begin{array}{c}\text { ECEL } \\
{[\mu \mathrm{m}]}\end{array}$ & 1380 & 965 & 30 \\
\hline $\begin{array}{c}\lambda_{\text {pearlite }} \\
{[\mu \mathrm{m}]}\end{array}$ & 0.33 & 0.23 & 30 \\
\hline $\begin{array}{l}\mathrm{D}_{\mathrm{IP}}^{\mathrm{Hyd}} \\
{[\mu \mathrm{m}]}\end{array}$ & 21 & 19 & 10 \\
\hline$\delta_{\text {uts }}[\mathrm{MPa}]$ & 284 & 286 & 1 \\
\hline
\end{tabular}

Figure 10: Microstructure of (1) C13D-Low cooling rate $(2.80 \% \mathrm{C})$ and (2) C13C-Medium cooling rate $(3.05 \% \mathrm{C})$. The arrows indicate the size of a typical eutectic cell and the red marked area shows a part of the inter-dendritic area $\left(\mathrm{A}_{\mathrm{IP}}\right)$.

However the derived correlation between $\mathrm{D}_{\text {Hyd }}^{\text {Hyd }}$ and UTS is similar but not identical with the modified Griffith's relation (Eq. 1). More specific the exponent of the Eq. 7 is found to be equal to 0.586 , somehow larger than the proposed exponent in the Griffith's relation (equal to -0.5 ). This discrepancy indicates a deficiency of the proposed model and shows that the experimental data could be adjusted in a different physical model where the effect of pearlite inter-lamellar spacing ( $\left.\lambda_{\text {pearlite}}\right)$ on UTS may be taken into consideration. Thus linear multiple regression analysis was made to determine the simultaneous influences of the $\mathrm{D}^{\mathrm{Hyd}}{ }_{\mathrm{IP}}$ and the $\lambda_{\text {pearlite }}$ on the UTS. The model obtained is based on the modified Hall-Petch relation (Eq. 4) and is shown in Eq. 8.

$$
\sigma_{\mathrm{UTS}}=70.9+\frac{491.2}{\sqrt{D_{I P}^{\text {Hyd }}}}+\frac{295.7}{\sqrt{D_{I P}^{\text {Hyd }} \cdot \lambda_{\text {pearlite }}}}
$$

where $\mathrm{D}_{\text {IP }}^{\mathrm{Hyd}}$ and $\lambda_{\text {pearlite }}$ are in $\mu \mathrm{m}$. 
Probably the initial stress levels are overestimated in Eq. 8 and $5\left(\mathrm{k}_{1}=70.9\right.$ and $80 \mathrm{MPa}$ respectively). It is likely that during the tensile test the formation of multiple cracks at the graphite lamellae tip or the graphite de-cohesion from the matrix can occur at lower initial stress levels due to the fact that the lamellar graphite iron shows a non-linear mechanical behavior.

Fig. 11 shows the predicted UTS from the Eq. 7 and 8 in comparison with the experimental data. The $\mathrm{R}^{2}$ values indicate that the modified Hall-Petch relation (Eq. 8) predicts with better accuracy the UTS values than the derived exponential relation (Eq. 7).

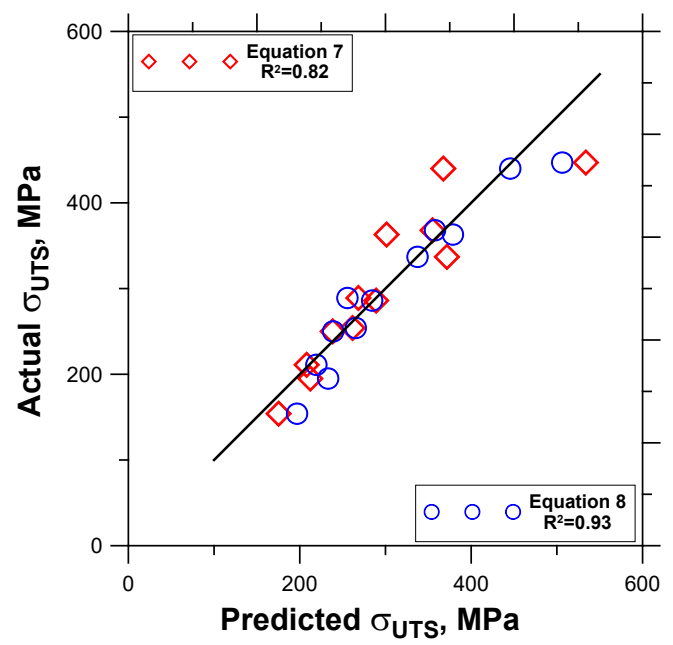

Figure 11: Measured and predicted UTS values.

\section{Conclusion}

High cooling rates refine the dendritic network, the eutectic cell structure, and the pearlite interlamellar spacing resulting in improved mechanical properties. Increasing carbon content mainly reduces the amount of the primary phase which negatively affects the mechanical properties.

The $\mathrm{D}^{\mathrm{HYD}}$ IP parameter expresses the ratio between the size and the coarseness of the area between the primary dendrites. This work shows that not the size of the graphite flakes but the $\mathrm{D}^{\mathrm{HYD}}{ }_{\text {IP }}$ is the main factor that determines the ultimate tensile strength in LGI.

The pearlite inter-lamellar spacing and Hydraulic Diameter of the Inter-dendritic Phase were used in a modified Hall-Petch equation for the modeling of UTS. The model developed can be applied across the whole spectrum of carbon content from eutectic to hypoeutectic composition, solidified at various cooling rates typical for both thin and thick walled complex shaped iron castings.

\section{Acknowledgements}

The present work was performed within the Swedish Casting Innovation Centre. Cooperating parties are Jönköping University, Scania CV AB, Swerea SWECAST AB and Volvo Powertrain Production Gjuteriet AB. Participating persons from these institutions/companies are acknowledged.

\section{References}

[1]. L. Collini, G. Nicoletto, R. Konecná, Microstructure and mechanical properties of pearlitic lamellar cast iron, Mat Sci Eng A - Struct 488 (2008) 529-539.

[2]. G.F. Ruff, J.F. Wallace, Effects of solidification structure on the tensile properties of lamellar iron, AFS Transactions 56 (1977) 179-202.

[3]. C. Bates, Alloy element effect on lamellar iron properties: part II, AFS Trans. 94 (1986) 889905. 
[4]. H. Nakae, H. Shin, Effect of graphite morphology on tensile properties of flake graphite cast iron, Mater Trans 42 (2001) 1428-1434.

[5]. T.J. Baker, The fracture resistance of the flake graphite cast iron, Materials in Engineering Applications 1 (1978) 13-18.

[6]. D.D. Goettsch and J.A. Dantzig, Modeling microstructure development in gray cast irons, Metall Mater Trans A, 25 (1994), 1063-1079.

[7]. V. Fourlakidis and A. Diószegi, A generic model to predict the ultimate tensile strength in pearlitic lamellar graphite iron, Mat Sci Eng A - Struct 618 (2014) 161-167.

[8]. D.A. Porter and K.E. Easterling, Dynamic studies of the tensile deformation and fracture of pearlite, Acta Metall 26 (1978), 1405-1422.

[9]. A. Catalina, X. Guo, D.M. Stefanescu, L. Chuzhoy, M.A. Pershing, Prediction of room temperature microstructure and mechanical properties in lamellar iron castings, AFS Trans. 94 (2000) 889-912.

[10]. A. Diószegi, V. Fourlakidis, I.L. Svensson, Fracture mechanics of lamellar cast iron, Solidification and Gravity V, Trans Tech Publications, Switzerland, Materials Science Forum 649 (2010), 517-522.

[11]. A. Diószegi, V. Fourlakidis, R. Lora, Austenite Dendrite Morphology in Lamellar Cast Iron, Int J Cast Metal Res, 28(Issue 5) (2015), 310-317. 